\title{
A ANÁLISE PROTEÔMICA NO CONTEXTO FORENSE
}

\author{
THE PROTEOMIC ANALYSIS IN THE FORENSIC CONTEXT
}

Larissa Dutra Bittencourt de Oliveira*, Carlos Eduardo Palhares Machado ${ }^{* *}$

Resumo

Realizou-se uma revisão de literatura consultando as bases de dados Medline, LILACS, BBO e Scielo, de 1997 a 2017, com o objetivo de ressaltar a importância do estudo da proteômica e sua aplicação nas diversas áreas forenses. Conclui-se que a evolução da tecnologia de espectrometria de massa juntamente com os bancos de dados proteômicos aplicados para o estudo das proteínas do corpo humano são de grande importância no contexto forense e podem fornecer subsídios nas diversas áreas da Criminalística, assim como na identificação e diferenciação de fluidos, tecidos e órgãos do corpo humano; na Criminologia no diagnóstico de doenças mentais; na Arqueologia e na Antropologia Forense no estudo da evolução das espécies, na estimativa da ancestralidade, do sexo, da cor dos olhos e cabelo e da idade, auxiliando nos processos de identificação humana.

Palavras-chave

Proteômica. Espectrometria de massa. Ciências Forenses. Genética Forense. Antropologia Forense.

Abstract

It was performed a literature review on Medline, LILACS, BBO and Scielo databases from 1997 to 2012 in order to highlight the importance of the study of proteomics and its application in the various forensic areas. It is concluded that the evolution of the technology of mass spectrometry together with the proteomic databases applied to the study of proteins of the human body are of great importance in the forensic context and can provide subsidies in the different areas of Criminalistics as well as in the identification and differentiation of fluids, tissues and organs of the human body; in Criminology in the diagnosis of mental illness; in Archeology and Forensic Anthropology in the study of the evolution of species, in the estimation of ancestry, sex, eye color and hair and age, aiding in the processes of human identification.

KeYwords

Proteomic. Mass spectrometry. Forensic Sciences. Forensic Genetics. Forensic Anthropology.

\section{INTRODUÇÃO}

A proteômica surge como área complementar ao estudo do genoma (WILHELM et al., 2014). O campo alcançado tem testemunhado enorme desenvolvimento na última década, principalmente através de avanços na

Correspondence Authors:

Larissa Dutra Bittencourt de Oliveira. larissadbo@gmail.com. Rua Sampaio 344/202, Centro, Juiz de Fora, MG, CEP: 36010-360. Telefone: (32) $98867-$ 1164

Carlos Eduardo Palhares Machado. palhares.cepm@dpf.gov.br. Edifício INC, SPO, Quadra 07, Lote 23, Asa Sul. Brasília DF, CEP: 70610-200. Telefone: (061) 2024-9834

Mestre em Clínica Odontológica pela Universidade Federal de Juiz de Fora (UFJF); pós-graduanda em Perícia Criminal e Ciências Forenses no Instituto de Pós-Graduação e Graduação (IPOG). larissadbo@gmail.com

Doutor em Ciências pela Faculdade de Medicina de Ribeirão Preto, Universidade de São Paulo (USP). Perito criminal federal - Área de Odontologia - Polícia Federal. Professor no curso de Pós-Graduaçâo em Perícia Criminal e Ciências Forenses do Instituto de Pós-Graduação e Graduação (IPOG). palhares.cepm@dpf.gov.br

Received: 03/2017

Accepted: 05/2017 espectrometria de massa (MS - Mass Spectrometry) e na bioinformática com uma infinidade de softwares disponíveis que podem converter os gigabytes da MS em milhares de identificaçôes peptídicas (MUÑOZ; HECK, 2014). Essas abordagens aumentam a confiabilidade da identificação proteica, porque a precisão a ser alcançada nos peptídeos derivados da proteína é muito maior (algumas partes por milhão) (PATEL et al., 2016).

A capacidade da espectrometria de massa para identificar quantidades mínimas de proteínas de misturas cada vez mais complexas é a principal força motriz da proteômica (TYERS; MANN, 2003). Uma vez identificadas, a MS baseada em ensaios-alvo facilita a detecção e a quantificação inequívoca de proteínas de baixa abundância, em um contexto de outras moléculas não alvo. Essa abordagem resultou em uma riqueza de novas oportunidades para desenvolver pesquisas baseadas em proteínas para aplicaçóes forenses (HU et al., 2005; KENTSIS et al., 2009), levando 
em conta que muitas vezes as amostras coletadas nessas situações são em quantidades ínfimas e de difícil detecçẫo.

Assim, é de grande importância revisar a literatura para maiores esclarecimentos sobre o estudo da proteômica e sua evolução no auxílio e na aplicação dentro das diversas áreas forenses.

\section{REVISÃO DE LITERATURA/DISCUSSÁO}

Todas as células vivas são constituídas por proteínas, responsáveis por uma multiplicidade de funçôes essenciais necessárias para a manutenção da vida (LINDSKOG, 2015), representando os principais componentes das vias fisiológicas e metabólicas das células (ABHILASH, 2009). As proteínas apresentam diferentes funçóes celulares capazes de expressar genes, catalisar reaçôes metabólicas e compor a parte estrutural de uma célula, são feitas de cadeias de moléculas menores chamadas aminoácidos, que são geralmente mais resistentes que o DNA (DEMARCHI et al., 2016).

A palavra proteoma é derivada de proteínas expressas por um genoma, e refere-se a todo o complemento de proteínas produzidas pelo organismo, assim como o genoma é todo o conjunto de genes (ABHILASH, 2009). Segundo Wilhelm et al. (2014), os proteomas são caracterizados por grandes diferenças na abundância de proteínas, nos padrôes de expressão dependentes do tipo de célula, do tempo e de modificaçôes pós-translacionais, todas as quais possuem informaçôes biológicas não acessíveis pela genômica ou pela transcriptômica.

Considerando que o genoma é quase idêntico em cada célula do corpo humano e também relativamente constante ao longo da vida de um organismo (MUÑOZ; HECK, 2014), existem expressões proteicas em diferentes partes do corpo, em cada célula, e muda dramaticamente ao longo do tempo, em diferentes estágios do ciclo de vida e em diferentes condiçôes ambientais (ABHILASH, 2009; MUÑOZ; HECK, 2014).

Enquanto o genoma é uma entidade constante, o proteoma é uma entidade dinâmica (TYERS; MANN 2003), difere de célula para célula e está em constante mudança por interaçóes bioquímicas entre o genoma e o meio ambiente. Isto inclui modificaçóes feitas a um determinado conjunto de proteínas, que variam com o tempo e requisitos distintos, ou mesmo ao estresse que uma célula ou organismo sofre (ABHILASH, 2009). Além de detectar o nível de expressão do gene, o estado do desenvolvimento celular, as interaçôes gênicas e as diversas respostas celulares em relação às diferentes condições em que a célula está submetida, o estudo da proteômica torna possível uma análise mais detalhada e dinâmica da expressão gênica nos processos metabólicos dos seres vivos (EMIDIO et al., 2015; LINDSKOG, 2015).

Projetos iniciais do proteoma humano incluem: o mapa proteômico de Kim et al. (2014), cujos autores apresentaram mediçôes diretas de proteínas e peptídeos. Os resultados foram comparados com dois dos maiores bancos de dados de peptídeos humanos, o PeptideAtlas e GPMDB (The Global Proteome Machine Database). Uma estratégia única e abrangente para a análise proteogenômica permitiu descobrir uma série de novas proteínas; o banco de dados proteômicos de Wilhelm et al. (2014), cujos autores apresentaram um esboço extenso do Projeto do Proteoma Humano baseado em MS para análise em tempo real de um grande banco de dados público, chamado ProteomicsDB (https:www.proteomicssdb.org). O ProteomicsDB e recursos similares têm um papel a desempenhar nesses desafios, pois permitirão desenvolver ferramentas computacionais e reagentes laboratoriais, facilitando experimentos na descoberta de todo o proteoma, ensaios quantitativos de proteínas, bem como a exploração geral do proteoma humano; e o projeto de desenvolvimento do atlas de proteínas do corpo humano de Uhlén et al. (2015), cujos autores apresentaram um mapa detalhando a variaçáo molecular do proteoma nos diferentes tecidos e órgãos do corpo humano. O Atlas de Proteínas Humanas (Human Protein Atlas, www.proteinatlas.org) possibilita explorar proteínas expressas em níveis elevados nos diferentes tecidos e órgãos, analisar o perfil dos tecidos e determinar as classes de proteínas específicas destes, e também listar a localização das proteínas até o nível de célula única.

Essas abordagens aumentam a confiabilidade da identificação proteica, porque a precisão a ser alcançada nos peptídeos derivados da proteína é muito maior (algumas partes por milhão) (PATEL et al., 2016). Enquanto a espectrometria de massa permite quantificar um determinado conjunto de proteínas em uma amostra, a imuno-histoquímica tem a vantagem de adicionar resolução espacial e informação de expressóes padrão da estrutura de certas células (LINDSKOG, 2015). Não só as proteínas podem ser analisadas como também os diversos processos biológicos das células, suas isoformas, modificaçôes e interaçôes (TYERS; MANN, 2003). Além disso, permite a investigação da expressão de proteínas específicas para 
diferentes tecidos, fases de desenvolvimento ou processos biológicos, incluindo doenças (CAPPELLINI et al., 2014).

\section{A PROTEÔMICA E O CONTEXTO FORENSE}

\subsection{ARQUEOLOGIA E A ANTROPOLOGIA} FORENSE

Alteraçóes anatômicas em linhagens extintas de mamíferos durante o tempo evolutivo, como a perda de dedos, o rápido aumento do tamanho corporal, o desenvolvimento de uma pelagem espessa e reduçôes na área da superfície da orelha e da cauda de mamutes e rinocerontes são exemplos primordiais de evoluçáo adaptativa subjacente à exploraçáo de novos habitats. Esses processos dinâmicos são largamente controlados por proteínas que, por exemplo, formam canais celulares, que ligam, transportam e conduzem reaçóes químicas. No entanto, é provável que as especializações bioquímicas adotadas durante essas transiçôes evolutivas sejam de grande importância biológica (CAMPBELL; HOFREITER, 2015). A informação sistemática confiável através da sequenciação de proteínas resistentes à degradação é essencial para as investigações em biologia evolutiva, abrindo novas perspectivas no estudo da evoluçáo dos vertebrados (WELKER et al., 2015), em pesquisas paleobiológicas, na engenharia genômica e nas técnicas de diferenciação celular, além de pesquisas evolucionárias dentro da bioquímica, da genômica, da paleontologia e da biologia celular, adicionando novas dimensôes para o estudo da seleçáo natural de espécies extintas e existentes (CAMPBELL; HOFREITER, 2015).

O grande potencial da proteômica para a caracterizaçáo paleofisiológica de espécies extintas foi demonstrado por Cappellini et al. (2012) ao analisarem a sequência de proteínas ósseas antigas do fêmur dos restos mortais de um mamute siberiano macho de 43.000 anos. Essa técnica oferece novas perspectivas para inferências filogenéticas e estudos fisiológicos na investigação de amostras, nas quais o DNA antigo não é acessível devido à degradação fóssil. Wadsworth e Buckley (2014) relataram o uso de técnicas proteômicas para estudar o proteoma fóssil. Apesar de as proteínas sobreviverem por mais tempo que o DNA, estimase serem capazes de sobreviver por até um milhão de anos, mas pouco se sabe sobre a degradação delas ao longo do tempo. Cappellini et al. (2014) revisaram sobre a aplicaçáo de métodos proteômicos quantitativos em amostras antigas, que pode oferecer a oportunidade de reconstruir fenótipos fisiopatológicos caracterizados por padróes específicos de expressão proteica e não necessariamente codificados por DNA. Amostras antigas estáo revolucionando a compreensão do passado, fornecendo informaçóes sobre filogenia, migração, evolução, domesticação e extinção de espécies.

Há mais de cinquenta anos, Pauling e Zuckerkandl (1963) reconheceram que as proteínas de todas as espécies vivas contêm um registro do seu passado histórico e propuseram que a reconstrução da sequência ancestral poderia ser usada para deduzir suas estruturas primárias de polipeptídeos nos antepassados das espécies. Também sugeriram que estudos via restauração molecular dessas proteínas arcaicas poderiam ser sintetizados e usados para estudar as propriedades físico-químicas dessas moléculas e fazer inferências sobre suas funçóes.

As proteínas estâo entre as moléculas biológicas mais duradouras que podem ser isoladas de material antigo. Devido à sua estabilidade, elas tendem a ser mais resistentes do que os ácidos nucleicos, o que demonstra uma importante vantagem em condições que levam à degradação de moléculas (LINDGREN et al., 2011; CAPPELLINI et al., 2012; CAPPELLINI et al., 2014). O DNA pode se degradar no ambiente, às vezes, abaixo do nível que pode ser amplificado por PCR. No entanto, a proteína é quimicamente mais robusta que o DNA e persiste por períodos mais longos (DEMARCHI et al., 2016; PARKER et al., 2016). Abordagens usando DNA antigo têm fracassado, provavelmente devido à sua rápida degradação em diferentes ambientes (WELKER et al., 2015). A elevada sensibilidade da MS e a estabilidade das proteínas tornam esse método adequado para identificar amostras pequenas e antigas (STEENDAM et al., 2013; YANG, 2013; PATEL et al., 2016) inclusive em amostras parcialmente degradadas, não impedindo a sua identificação (YANG, 2013). Amostras com essas características - ínfima quantidade, antigas e até mesmo arqueológicas e/ou degradadas por diversos fatores são comumente encontradas nas diversas áreas das Ciências Forenses.

Demarchi et al. (2016) pesquisaram sobre a sequência de proteínas ligadas a superfícies minerais. Parece que os biominerais são uma excelente fonte de sequências de proteínas antigas, pois essas ligaçôes garantem a sobrevivência de um registro fóssil. O esmalte dentário é o tecido mais duro, mais denso e mais mineralizado dos vertebrados, devido à sua alta cristalinidade (STEWART 
et al., 2016). O elemento dental está sob proteção dos tecidos epitelial, conjuntivo, muscular e ósseo. Há também a proteção que o esmalte, a dentina e o cemento conferem às células e tecidos no interior da cavidade pulpar, guardando, assim, o conteúdo genético individual (TÜTKEN; VENNEMANN, 2011). Porém, esse conteúdo fornece informaçóes limitadas. Uma proteína encontrada no esmalte mais abundante envolvida no desenvolvimento dentário, denominada amelogenina ou AMEL, e expressa a partir dos cromossomos $\mathrm{X}$ e $\mathrm{Y}$ apresenta distinçóes entre os sexos quanto ao tamanho e ao padráo da sequência de nucleotídeos. O sequenciamento de regiôes peptídicas do dimorfismo do gênero pode ser útil na determinação do sexo, especialmente quando nenhum outro biomaterial está disponível, nem o DNA. Essa abordagem permite potenciais aplicaçóes em análises forenses (STEWART et al., 2016).

Um aspecto interessante da análise do esqueleto recente e antigo é a necessidade da reconstrução da aparência da pessoa falecida. $\mathrm{Na}$ análise de DNA antigo, a prediçáo de características particulares externamente visíveis não reflete nas características esqueléticas, como a cor dos olhos e do cabelo. Em análise esquelética, como em casos forenses, essa predição das características externas pode ser útil e informativa na investigação policial para revelar a identidade de uma pessoa morta, se outros meios (como STR, mtDNA e perfil Y-DNA) falharem (DRAUS-BARINI et al., 2013). Cabelos de indivíduos diferentes podem ser distinguidos por propriedades físicas. A análise proteômica revelou considerável variação no perfil entre as amostras de caucasianos, afro-americanos, quenianos e coreanos. Nesses grupos étnicos, proteínas proeminentes de queratina serviram para distinguir perfis individuais. Além de fornecer uma visão sobre a estrutura do cabelo, os achados atuais podem levar a melhorias na diferenciação de origens étnicas e oferecer uma abordagem para o uso de evidências de cabelo em cenas de crime na distinção entre indivíduos. Na grande maioria dos casos, somente o DNA mitocondrial (mtDNA) está disponível, podendo fornecer valiosas evidências de exclusão, mas não é suficiente sozinho para identificação individual. As informaçôes provenientes da caracterização proteômica complementam o exame microscópico e de DNA, e aumentam o seu valor probatório (LAATSCH et al., 2014). Parker et al. (2016) avaliaram o proteoma do eixo do cabelo humano e demonstraram que medidas quantificáveis da discriminaçáo da identidade e da ancestralidade biogeográfica podem ser obtidas a partir da detecção de peptídeos variantes na proteína do eixo do cabelo, incluindo pelos de contextos bioarqueológicos. As Ciências Forenses, nas quais o cabelo é muitas vezes um componente relevante em cenas de crime, e contextos bioarqueológicos, nos quais se tem uma ampla gama de condiçóes ambientais, dependem de métodos que identifiquem indivíduos de forma científica e estatisticamente válida. Essa população proteica proporciona uma representação suficientemente ampla do genoma para validar seu uso e desenvolver para os âmbitos forense e bioarqueológico medidas úteis de identidade e origem biogeográfica, despertando uma ferramenta adicional na Antropologia e na Genética Forense.

Andersen et al. (2013) apresentaram um método objetivo para medir a cor dos olhos que permite a pesquisadores associarem marcadores genéticos com diferentes tonalidades de cor. Informaçáo sobre o fenótipo do autor pode ser uma ferramenta valiosa em caso de crime se nenhum suspeito ou indivíduo do banco de dados de DNA corresponder ao perfil de STR encontrado na cena do crime. Com ensaios confiáveis de fenotipagem forense, os investigadores podem se concentrar em grupos de indivíduos com peculiaridades previstas pelas investigaçóes genéticas. Draus-Barini et al. (2013) testaram a viabilidade do sistema HIrisPlex no estabelecimento da cor dos olhos e do cabelo de restos esqueléticos de indivíduos mortos de variados intervalos de tempo post-mortem e condiçóes de armazenamento. Foi demonstrado que o sistema HIrisPlex é adequado, sensível e robusto para prever de forma confiável a cor dos olhos e cabelos de restos esqueletais antigos e contemporâneos, em variadas condiçôes de armazenamento, mostrando ser uma ferramenta promissora na rotina de investigaçôes forenses, estudos evolutivos e antropológicos futuros. Zhang et al. (2016) analisaram, identificaram e caracterizaram o proteoma da íris, do corpo ciliar, do complexo epitélio pigmentar da retina e coroide do olho humano através da MS, o que pode servir como um recurso valioso para futuras investigaçōes.

Entre outras abordagens promissoras, está a utilização de biomarcadores de proteínas para a identificação de manchas biológicas. Uma das vantagens significativas desses biomarcadores é a diversidade dos potenciais alvos que são possíveis em diferentes tecidos (HU et al., 2005; KENTSIS et al., 2009; BUTLER, 2011; CAPPELLINI et al., 2012; LINDGREN et al., 2011), mesmo sem a necessidade de nenhum conhecimento prévio da mancha desconhecida para realizar o teste (YANG, 2013).

Para a identificação de vestígios biológicos em local de crime, é fundamental que haja um método capaz de 
estabelecer uma relação unívoca entre os elementos em questáo, criando um conjunto de caracteres próprios que possa diferenciar pessoas ou coisas entre si (FUJIHARA et al., 2017). Enquanto a análise de DNA de um swab pode revelar a presença e um perfil de DNA compatível com uma alegada vítima, esse perfil isolado não indica se o DNA provém de saliva, secreção vaginal, urina ou outras fontes. A capacidade de associar um extrato de DNA a um tecido específico, no entanto, muitas vezes fornece informações contextuais críticas, pois os exames não sáo capazes de esclarecer a natureza da amostra coletada (BUTLER, 2011; LEGG et al., 2014).

Os métodos padrão são uma mistura de técnicas para a identificação de fluidos corporais (STEENDAM et al., 2013; YANG, 2013). Eles requerem a integridade estrutural dos marcadores e, além de não serem confirmatórios, apenas presuntivos, outras proteínas ou substâncias podem estar presentes, levando a um resultado falso positivo (STEENDAM et al., 2013; YANG, 2013; LEGG et al., 2014; PATEL et al., 2016; FUJIHARA et al., 2017) e à necessidade de realização de vários testes diferentes para a identificação desses fluidos corporais (YANG, 2013; FUJIHARA et al., 2017). Foram realizadas pesquisas sobre o isolamento e a identificação de biomarcadores de proteínas altamente específicos de manchas biológicas com utilidade forense na identificação de traços de saliva humana, fluido seminal, urina, fluido vaginal, sangue periférico, fluido menstrual (STEENDAM et al., 2013; YANG, 2013; LEGG et al., 2014; IGOH; DOI; SAKURADA, 2015; DAMMEIER et al., 2016; PATEL et al., 2016) e, em menor grau, secreçôes nasais, fezes, e urina (STEENDAM et al., 2013). Os métodos utilizados com a tecnologia de MS foram capazes de detectar e determinar múltiplos marcadores de proteínas dos diferentes fluidos corporais em um único teste confirmatório (STEENDAM et al., 2013; YANG, 2013; LEGG et al., 2014; DAMMEIER et al., 2016; IGOH; DOI; SAKURA, 2015; PATEL et al., 2016). Além de a análise náo ser destrutiva para o DNA, também pode ser usada como exploração (STEENDAM et al., 2013; FUJIHARA et al., 2017), como em uma amostra de 9 anos de idade que foi submetida na época a tratamento químico usado para realçar a visualização do sangue, abrindo, assim, novas oportunidades forenses para a revisão de casos estacionados (PATEL et al., 2016). A identificação do fluido nos exames forenses contribui para a evidência do caso, orienta o curso de novas investigaçóes e também complementa o conjunto de provas. Tais avanços tecnológicos tornaram a MS o padrão-ouro para a identificação correta do fluido corporal (YANG, 2013). Essa eficácia e impacto na prática forense acelera as investigaçóes laboratoriais, fornece muito mais evidências confiáveis e informativas no sistema de justiça criminal.

Esse tipo de tecnologia também pode ser empregado na análise dos projetis de arma de fogo, auxiliando a autópsia da Medicina Legal. Enquanto é rotina identificar qual projétil atingiu um sujeito por análise de DNA do material sobre a superfície do projétil, é bastante difícil determinar qual projétil causou a lesão letal - muitas vezes o ponto crucial no processo judicial. Dammeier et al. (2016) investigaram o material biológico da superfície de um projétil e determinaram os tecidos atravessados por ele. A análise proteômica baseada em MS foi capaz de atingir uma precisão de classificação de órgãos de 99\%. Foi analisado um caso real de assassinato, no qual o legista não foi capaz de reconstruir totalmente o trajeto da bala durante a autópsia, e, do ponto de vista forense, era de interesse específico saber qual dos múltiplos disparos foi letal. As proteínas específicas encontradas correlacionaram com a determinaçáo do trajeto da bala feito na autópsia clássica. Esses conceitos podem ser aplicados na reconstrução mecânica ou balística do evento em uma análise mais abrangente.

$\mathrm{Na}$ Criminologia, o diagnóstico de doenças mentais pode ser de difícil e demorada conclusão. Modificaçôes genéticas que alteram a estrutura celular proteica levam a defeitos morfológicos ou mesmo a sua ausência. Tal fato acarreta doenças ou demonstra ser marcador específico destas. As alterações nos genes, seus transcritos e mudanças nas proteínas nos processos celulares são alvos de importantes estudos na determinaçáo de marcadores proteicos para o desenvolvimento de novos métodos de diagnósticos e terapêuticos (WANG et al., 2014) com utilidade clínica e laboratorial, emergindo como uma ferramenta de validação na descoberta de biomarcadores (WANG et al., 2014; EMIDIO et al., 2015; LINDSKOG, 2015). Awam et al. (2015) pesquisaram sobre a abordagem genômica e proteômica utilizando a MS em busca de biomarcadores específicos da esquizofrenia. A análise identificou esses biomarcadores diferenciando os pacientes com a doença e comprovando ser promissor no diagnóstico mais preciso da doença e nas investigaçóes de condiçóes psiquiátricas. Haggmark et al. (2016) forneceram uma visão geral de novas tecnologias, como a proteômica e a MS, na busca de proteínas relacionadas às doenças neurológicas, destacando as desordens psiquiátricas como a esquizofrenia e a 
depressão. Foram encontrados perfis associados à doença e verificados com sucesso.

A toxicologia forense também não fica de fora dessa moderna tecnologia. Os dados de expressão proteica através de biomarcadores da eficácia e da toxicidade de drogas (ABHILASH, 2009) prometem informativo e discriminatório para beneficiar no diagnóstico, na descoberta de fármacos e na elucidação de mecanismos da ação de drogas (TYERS; MANN, 2003; LINDSKOG, 2015). A maioria das drogas farmacêuticas têm alvo nas proteínas (EMIDIO et al., 2015; LINDSKOG, 2015), e muitos estudos toxicológicos têm aproveitado a estabilidade do esmalte dentário para estudar exposiçôes a metais pesados (STEWART et al., 2016). Chen et al. (2012) investigaram marcadores de injúrias tóxicas com o objetivo de elucidar mecanismos de intoxicação por metanol a nível proteico através da tecnologia proteômica, avaliando as variaçóes na expressão de proteínas na retina de ratos. A análise proteômica mostrou que a expressão de várias proteínaschave foram alteradas pela intoxicaçáo por metanol. Essas descobertas abrem caminho para estudos toxicológicos futuros.

Assim como o exame de DNA pode comprovar ou negar a autoria de um crime, transformando-se em meio de prova eficaz para a veracidade de processos penais, a análise proteômica poderá ser útil nos exames de corpo de delito comprovando a materialidade, adentrando no campo da autoria e da dinâmica (BUTLER, 2011; DAMMEIER et al., 2016), aumentando o rol de provas objetivas e fundamentadas de forma técnica e científica dentro das análises forenses.

\section{CONCLUSÃO}

Fundamentando-se na literatura pesquisada, podese concluir que a evolução da tecnologia avançada de alta resolução e sensibilidade da espectrometria de massa em conjunto com banco de dados proteômicos com foco no estudo das proteínas humanas representa um recurso inestimável para a obtenção de conhecimentos em diversas áreas, inclusive com importantes aplicaçōes forenses. Esse estudo aprofundado das proteínas pode auxiliar em amostras biológicas na identificação e diferenciação de fluidos corporais, tecidos e órgãos humanos encontrados em cenas de crimes através de uma análise conclusiva e em única etapa, para as quais hoje são aplicados variados testes, e apenas presuntivos. Pode também auxiliar nos exames de corpo de delito, inclusive toxicológico; auxiliar no diagnóstico de doenças mentais em Criminologia, aumentando a confiabilidade nos resultados $\mathrm{e}$ consequentemente favorecendo a justiça; e ainda auxiliar na área de Arqueologia e Antropologia Forense no estudo da evolução das espécies, estimando ancestralidade, sexo, cor dos olhos e do cabelo graças à estabilidade e resistência das proteínas em condiçóes degradantes.

\section{REFERÊNCIAS}

ABHILASH, M. Applications of proteomics. The Internet Journal of Genomics and Proteomics, v. 4, n. 1, p. 01-07, 2009.

ANDERSEN, J. D.; JOHANSEN, P.; HARDER, S.; CHRISTOFFERSEN, S. R.; DELGADO, M. C.; HENRIKSEN, S. T. et al. Genetic analyses of the human eye colours using a novel objective method for eye colour classification. Forensic Science International: Genetics, v. 7, p. 508-515, 2013.

AWAM, K. A.; HAUßLEITER, I. S.; DUDLEY, E.; DONEV, R.; BRÜNE, M.; JUCKEL, G. et al. Multiplatform metabolome and proteome profiling identifies serum metabolite and protein signatures as prospective biomarkers for schizophrenia. Journal of Neural Transmission, v. 122 n. 1, p. S111-S122, 2015. DOI $10.1007 / s 00702-014-1224-0$.

BUTLER, J. M. Advanced topics in forensic DNA typing: sample collection, storage, and characterization. Academic Press, New York, p. 1-19, 2011.

CAMPBELL, K. L.; HOFREITER, M. Resurrecting phenotypes from ancient DNA sequences: promises and perspectives. Canadian Journal of Zoology, v. 93, p. 701-710, 2015.

CAPPELLINI, E.; JENSEN, L. J.; SZKLARCZYK, D.; GINOLHAC, A.; DA FONSECA, R. A.; STAFFORD, T. W. et al. Proteomic analysis of a pleistocene mammoth femur reveals more than one hundred ancient bone proteins. Journal of Proteome Research, v. 11, p. 917-926, 2012. DOI:10.1021/pr200721u.

CAPPELLINI, E.; COLLINS, M. J.; GILBERT, M. T. P. Unlocking ancient protein palimpsests. Science, v. 343 , n. 6.177 , p. $1.320-$ 1.322, 2014. DOI:10.1126/science.1249274. PMID: 24653025.

CHEN, J. M.; ZHU, G. Y.; XIA, W. T.; ZHAO, Z. Q. Proteomic analysis of rat retina after methanol intoxication. Toxicology, v. 293, p. 89-96, 2012.

DAMMEIER, S.; NAHNSEN, S.; VEIT, J.; WEHNER, F.; UEFFING, M.; KOHLBACHER, O. Mass-spectrometry-based proteomics reveals organ-specific expression patterns to be used as forensic evidence. Journal of Proteome Research, Washington, v. 15, p. 182-192, 2016. DOI: 10.1021/acs.jproteome.5b00704. 
DEMARCHI, B.; HALL, S.; RONCAL-HERRERO, T.; FREEMAN, C. L.; WOOLLEY, J.; CRISP, M. K. et al. Protein sequences bound to mineral surfaces persist into deep time. eLife, v. 5, p. e17.092, 2016. DOI: 10.7554/eLife.17092.

DRAUS-BARINI, J.; WALSH, S.; POŚPIECH, E.; KUPIEC, T.; GEĄB, H.; BRANICKI, W. et al. Bona fide colour: DNA prediction of human eye and hair colour from ancient and contemporary skeletal remains. Investigative Genetics, v. 4, n. 3, p. 1-15, 2013.

EMIDIO, N. B.; CARPANEZ, A. G.; QUELLIS, L. R.; FARANI, P. S.; VASCONCELOS, E. G.; PINTO, P. F. Proteômica: uma introdução aos métodos e aplicaçóes. HU Revista, Juiz de Fora, v. 41, n. 3 e 4, p. 101-111, 2015.

FUJIHARA, J.; FUJITA, Y.; YAMAMOTO, T.; NISHIMOTO, N.; KIMURA-KATAOKA, K.; KURATA, S. et al. Blood identification and discrimination between human and nonhuman blood using portable Raman spectroscopy. International Journal of Legal Medicine, v. 131, p. 319-322, 2017. DOI: 10.1007/s00414-0161396-2.

HÄGGMARK, A.; SCHWENK, J. M.; NILSSON, P. Neuroproteomic profiling of human body fluids. Proteomics Clinical Applications, v. 10, p. 485-502, 2016. DOI: 10.1002/ prca.201500065.

HU, S.; XIE, Y.; RAMACHANDRAN, P.; OGORZALEK LOO, R. R.; LI, Y.; LOO, J. A.; WONG, D. T. Large-scale identification of proteins in human salivary proteome by liquid chromatography/ mass spectrometry and two-dimensional gel electrophoresis-mass spectrometry. Proteomics, v. 5, p. 1.714-1.728, 2005. DOI: 10.1002/pmic.200401037.

IGOH, A.; DOI, Y.; SAKURADA, K. Identification and evaluation of potential forensic marker proteins in vaginal fluid by liquid chromatography/mass spectrometry. Analytical and Bioanalytical Chemistry, v. 407, p. 7.135-7.144, 2015. DOI: $10.1007 /$ s00216015-8877-x.

KENTSIS, A.; MONIGATTI, F; DORFF, K.; CAMPAGNE, F.; BACHUR, R.; STEEN, H. Urine proteomics for profiling of human disease using high accuracy mass spectrometry. Proteomics Clinical Applications, v. 3, p. 1.052-1.061, 2009.

KIM, M. S.; PINTO, S. M.; GETNET, D. et al. A draft map of the human proteome. Nature, London, v. 509, p. 575-581, 2014. DOI:10.1038/nature13302.

LAATSCH, C. N.; DURBIN-JOHNSON, B. P.; ROCKE, D. M.; MUKWANA, S.; NEWLAND, A. B.; FLAGLER, M. J. et al. Human hair shaft proteomic profiling: individual differences, site specificity and cuticle analysis. Peer Journal, v. 2, p. 1-17, 2014. DOI: $10.7717 /$ peerj. 506 .
LEGG, K. M.; POWELL, R.; REISDORPH, N.; REISDORPH, R.; DANIELSON, P. B. Discovery of highly specific protein markers for the identification of biological stains. Electrophoresis, Weinhein, v. 35, p. 3.069-3.078, 2014. DOI: 10.1002/elps.201400125.

LINDGREN, J.; UVDAL, P.; ENGDAHL, A.; LEE, A. H.; ALWMARK, C.; BERGQUIST, K. E. et al. Microspectroscopic evidence of cretaceous bone proteins. PLOS ONE, v. 6, n. 4, p. e19.445, 2011. DOI: 10.1371/journal.pone.0019445.

LINDSKOG, C. The potential clinical impact of the tissue based map of the human proteome. Expert Review of Proteomics, United Kingdom, v. 12, n. 3, p. 213-215, 2015. DOI: 10.1586/14789450.2015.1040771.

MUNOOZ, J.; HECK, A. J. R. From the human genome to the human proteome. Angewandte Angewandte Chemie International Edition, v. 53, p. 10.864-10.866, 2014. DOI: 10.1002/ anie. 201406545 .

PARKER, G. J.; LEPPERT, T.; ANEX, D. S.; HILMER, J. K.; MATSUNAMI, N.; BAIRD, L. et al. Demonstration of proteinbased human identification using the hair shaft proteome. PLOS ONE, v. 11, n. 9, p. 1-26, 2016. DOI:10.1371/journal. pone. 0160653 .

PATEL, E.; CICATIELLO, P.; DEININGER, L.; CLENCH, M. R.; MARINO, G.; GIARDINA, P. A proteomic approach for the rapid, multi-informative and reliable identification of blood. Analyst, United Kingdom, v. 141, p. 191-198, 2016. DOI: 10.1039/c5an02016f.

PAULING, L.; ZUCKERKANDL, E. Molecular "Restoration Studies" of extinct forms of life. Acta Chemica Scandinavica, v. 17, n. 1, p. S9-16, 1963.

STEENDAM, K. V.; CEULENEER, M. D.; DHAENENS, M.; HOOFSTAT, D. V.; DEFORCE, D. Mass spectrometry-based proteomics as a tool to identify biological matrices in forensic science. International Journal of Legal Medicine, Washington, v. 127, p. 287-298, 2013. DOI: 10.1007/s00414-012-0747-x.

STEWART, N. A.; MOLINA, G. F.; ISSA, J. P. M.; YATES, N. A.; SOSOVICKA, M.; VIEIRA, A. R. et al. The identification of peptides by nanoLC-MS/MS from human surface tooth enamel following a simple acid etch extraction. Royal Society of Chemistry Advances, v. 6, p. 61.673-61.679, 2016. DOI: 10.1039/c6ra05120k.

TÜTKEN, T.; VENNEMANN, T. W. Fossil bones and teeth: preservation or alteration of biogenic compositions? Palaeogeography, Palaeoclimatology, Palaeoecology, v. 310, p. 1-8, 2011. DOI: 10.1016/j.palaeo.2011.06.020.

TYERS, M.; MANN, M. From genomics to proteomics. Nature, Londres, v. 422, p. 193-197, 2003. DOI: 10.1038/nature01510. 
UHLÉN, M.; FAGERBERG, L.; HALLSTRÖM, B. M.; LINDSKOG, C.; OKSVOLD, P.; MARDINOGLU, A. et al. Tissue-based map of the human proteome. Science, Washington, v. 347, n. 6.220, p. 394, 2015. DOI: 10.1126/science.1260419.

WANG, K.; HUANG, C.; NICE, E. Recent advances in proteomics: towards the human proteome. Biomedical Chromatography, v. 28, p. 848-857, 2014. DOI: 10.1002/bmc.3157.

WADSWORTH, C.; BUCKLEY, M. Proteome degradation in fossils: investigating the longevity of protein survival in ancient bone. Rapid Communications in Mass Spectrometry, v. 28, p. 605-615, 2014. DOI: 10.1002/rcm.6821.

WELKER, F.; COLLINS, M. J.; THOMAS, J. A.; WADSLEY, M.; BRACE, S.; CAPPELLINI, E. Ancient proteins resolve the evolutionary history of Darwin's South American ungulates. Nature, v. 522, p. 81-84, 2015. DOI: 10.1038/nature14249.

WILHELM, M.; SCHLEGL, J.; HAHNE, H. et al. Massspectrometry-based draft of the human proteome. Nature, London, v. 509, p. 582-587, 2014. DOI: 10.1038/nature13319.

YANG, H.; ZHOU, B.; DENG, H.; PRINZ, M.; SIEGEL, D. Body fluid identification by mass spectrometry. International Journal of Legal Medicine, Washington, v. 127, p. 1.065-1.077, 2013. DOI 10.1007/s00414-013-0848-1.

ZHANG, P.; KIRBY, D.; DUFRESNE, C.; CHEN, Y.; TURNER, R.; FERRI, S. et al. Defining the proteome of human iris, ciliary body, retinal pigment epithelium, and choroid. Proteomics, v. 16, p. 1.146-1.153, 2016. DOI 10.1002/pmic.201500188. 